\title{
Bovine Tuberculosis and the Establishment of an Eradication Program in the United States: Role of Veterinarians
}

\author{
Mitchell V. Palmer and W. Ray Waters \\ Infectious Bacterial Diseases of Livestock Research Unit, National Animal Disease Center, Agricultural Research Service, \\ United States Department of Agriculture, 1920 Dayton Avenue, Ames, IA 50010, USA \\ Correspondence should be addressed to Mitchell V. Palmer, mitchell.palmer@ars.usda.gov
}

Received 10 January 2011; Revised 15 February 2011; Accepted 10 March 2011

Academic Editor: Jesse M. Hostetter

Copyright (C 2011 M. V. Palmer and W. R. Waters. This is an open access article distributed under the Creative Commons Attribution License, which permits unrestricted use, distribution, and reproduction in any medium, provided the original work is properly cited.

The significance of the identification of Mycobacterium bovis as a zoonotic pathogen in 1882 was not initially recognized. After years of research by veterinarians, and other scientists, the importance of $M$. bovis as a pathogen and the public health ramifications, were appreciated. Veterinarians played pivotal roles in the creation of improved meat and milk inspection, diagnosis of $M$. bovis infected cattle, and in time, a bovine tuberculosis eradication program that would impact every cattle producer in the country. After overcoming many challenges, the 93 -year-long program has decreased disease prevalence from $5 \%$ to $<0.001 \%$. Today, years of hard work by practitioners, researchers and regulatory officials alike, have yielded a program with a net benefit of almost $\$ 160$ million per year.

\footnotetext{
"There is perhaps no single disease that has aroused more interest and that is of greater significance to the livestock industry of this country than bovine tuberculosis [1].”-Veranus A. Moore, State Veterinarian of New York (1911).
}

\section{Ancient Origins of Mycobacterium bovis in North America}

The Mycobacterium tuberculosis complex is composed of several related species, including M. tuberculosis, Mycobacterium bovis, Mycobacterium africanum, Mycobacterium microti, Mycobacterium canettii, Mycobacterium pinnipedii, Mycobacterium caprae, and the recently identified Mycobacterium mungi [2]. Genomic analysis suggests that animal-adapted strains of $M$. bovis evolved from human-adapted strains of $M$. tuberculosis or a recent ancestor common to both M. tuberculosis and M. bovis, similar to M. africanum [3]. DNA sequencing of fossils, containing lesions consistent with tuberculosis, suggests that $M$. tuberculosis complex was present in North America during the Pleistocene era
[4]. Others propose that bovids carried M. tuberculosis complex over the Bering Strait during the late Pleistocene era and that tuberculosis was present when settlers arrived in North America. Still others believe tuberculosis accompanied settlers upon their arrival to North America [5].

\section{Human versus Bovine Tuberculosis: Koch's Assumptions}

A clear understanding of the relationship between $M$. tuberculosis, M. bovis, and disease in humans and animals has historically been a source of debate. In 1882, Robert Koch declared that the tubercle bacilli from humans and cattle were one and the same, and accordingly, human and bovine forms of tuberculosis were identical. In so doing, Koch 
apparently overlooked the work of the French physician, Jean Antoine Villemin, who in 1868, using rabbits, described the greater virulence of the bovine tubercle bacillus compared to the human tubercle bacillus [6]. Less widely known were declarations from veterinarians such as James Law of Cornell University, who, in 1877, stated that bovine tuberculosis was a communicable disease, transmitted through inoculation or ingestion of the tubercle. He also emphasized the danger tuberculosis represented for highly prized herds as well as humans. Although a highly controversial position to take, Law believed that humans could become infected from eating undercooked meat or fresh milk from tuberculous cattle [7]. Law's opinion was bolstered in 1883 by a resolution from the Fourth International Veterinary Congress at Brussels, which recommended that tuberculous cows only be used for human consumption when disease was localized and the animal was still in good physical condition. They also advised against consumption of milk from tuberculous cows [7].

Following Koch's announcement, veterinarians, bacteriologists, and others set out to conduct comparative observations on the virulence of bacilli from cattle and humans. Tubercle bacilli from cattle were transmitted, often with fatal consequences, to horses, donkeys, swine, cats, dogs, sheep, goats, rabbits, guinea pigs, and by accidental inoculation, humans. In 1900 Ravenel, a physician from South Carolina, reported that three Pennsylvania veterinarians, in separate incidents, were infected with the bovine tubercle bacillus via accidental skin inoculation while performing postmortem examinations [8]. Similar accounts were reported, as well as numerous case reports of infection resulting from ingestion of milk from tuberculous cows [9].

In 1883, shortly after Koch's announcement, physicians, Emanuel Klein and Heneage Gibbs, noted differences between bovine and human tubercle bacilli, and conducted small animal experiments with material obtained from tuberculous cows. They repeatedly showed the guinea pig was susceptible to both human and bovine tubercle bacilli; however, the rabbit was only susceptible to bovine tubercle bacilli [6]. Veterinarian Edmond Nocard, of the Veterinary College, Alfort, Paris stated, "all mammalia, including monkeys, become tuberculous after ingestion of milk from tuberculous cows. It would be absurd to contend that man alone offers an exception to the rule" [10]. Experimental transmission studies conducted by Theobald Smith, a physician scientist working for the Veterinary Division of the Bureau of Animal Industry (BAI, precursor to the present day Agricultural Research Service in USDA), and veterinarians Austin Peters and Langdon Frothingham, used calves experimentally inoculated with sputum from tuberculous humans to demonstrate that human bacilli possessed a low virulence for cattle [11]. Smith should be credited with being one of the first to observe differences between human and bovine tubercle bacilli. In 1895, Smith visited Koch in Europe and described his findings. By 1901, Koch had concluded that there was a difference between the bovine and human tubercle bacilli, but that there was little danger of transmission of the bovine bacillus to man. Koch reported these findings at the 1901 Tuberculosis Congress in London, absent credit to Smith. Recognition for Smith's findings would not come until the 1908 International Congress on Tuberculosis in Washington, DC [12]. Koch's assertion that the bovine tubercle bacillus posed minimal risk to humans was ardently challenged by leading veterinarians, such as Edmond Nocard, Bernard Bang, and John McFadyean who, in the interest of public health, were working towards eliminating bovine tuberculosis. Needless to say, the battle to repress bovine tuberculosis did not begin without debate. Many accepted Koch's view that tuberculosis of cattle was no danger to humans [13]. Given his prominent standing in the field of tuberculosis, this opinion was widely embraced, by all but a few scientists. An excerpt from Koch's remarks at the 1901 Tuberculosis Congress in London illustrates the obstacle faced by veterinarians and public health authorities that did not share Koch's opinion:

"I should estimate the extent of infection by the milk and flesh of tubercular cattle, and the butter made of their milk, as hardly greater than that of hereditary transmission, and I, therefore, do not deem it advisable to take any measures against it."

Koch's statement on the minimal risk associated with consuming milk or meat from tuberculous cows, had farreaching ramifications and led to various mistaken beliefs. Case in point, as late as 1928, prominent scientists such as Nobel prize winner Emil von Behring and Albert Calmette, coinventor of the vaccine Bacillus Calmette-Guerin (BCG) believed that bovine bacilli, after long residence in the human body, took on characteristics of the human bacilli [14].

After being faced with evidence from other scientists, by 1908 at the Sixth International Congress on Tuberculosis, Koch modified his position, stating [14]:

"I admit that bovine infection can occasionally
occur, and I desire not to be understood as
disregarding the endeavors to extirpate bovine
tuberculosis, as far as these endeavors are dic-
tated by agricultural and economic reasons. But
I mean that it would be wrong to give to those
proposals the leading place in front of the efforts
to combat human tuberculosis."

Koch clearly felt that the public health aspects of bovine tuberculosis were minimal and that eradication efforts should be motivated by animal health and economic concerns. The debate left both layperson and government policy maker confused concerning the proper amount of public health concern to provide bovine tuberculosis. Many governments engaged the opinion of expert scientists for advice. In Great Britain, a Royal Commission on Tuberculosis was formed to review the current knowledge and provide guidance to policy makers. The Pennsylvania State Livestock Sanitary Board, the New York City Health Department, the US BAI, and the American Veterinary Medical Association carried out similar investigations $[14,15]$. One member of the Royal Commission was noted veterinary scientist Sir John McFadyean. In their Interim Report of 1907, it was clear that they felt Koch was in error, stating: 


\begin{abstract}
"Facts indicate that a very large proportion of tuberculosis contracted by ingestion is due to tubercle bacilli of bovine source.... A very considerable amount of disease and loss of life, especially among the young, must be attributed to the consumption of cows' milk containing tubercle bacilli.... Our results clearly point to the necessity of measures more stringent than those presently enforced be taken to prevent the sale or the consumption of such milk."
\end{abstract}

\section{Variability in Virulence between Isolates}

Despite apparent host preferences between bovine and human tubercle bacilli, numerous studies near the turn of the century suggested that cattle and humans were susceptible to both pathogens. In 1898, Ravenel of the Pennsylvania Livestock Sanitary Board fed human sputum to four calves resulting in tuberculous lesions in all four, including extensive lesions in two of the animals [16]. Ravenel also intravenously inoculated a calf with a suspension of a culture obtained from a tuberculous mesenteric gland from a child that had died of tuberculous meningitis - the calf died 17 days later with severe tuberculous nodules within the lungs and liver [16]. In 1902, addressing the American Public Health Association in New Orleans, veterinarian microbiologist, Daniel E. Salmon presented reports of inoculation of tuberculous material from humans into cattle by various routes resulting in lesions and often, severe disease [16]. The French veterinarian JeanBaptiste Chauveau also demonstrated that administration of lung emulsions from tuberculous humans to cattle resulted in severe tuberculous lesions [9]. In contrast, performing studies for the British Royal Tuberculosis commission of 1895, professor and physician Sidney Martin demonstrated that sputum from man was less virulent for animals than was tubercular material from cattle [9]. Others were unable to infect cattle with human tuberculous material. The variability in outcome between the studies is not surprising considering early reports of wide-ranging virulence of the human tubercle bacillus [17]. Kossel, speaking on behalf of a Koch-appointed German tuberculosis commission, also reported differences in virulence between bovine isolates [9]. The German commission tested 39 different freshly prepared cultures made from tuberculous lesions obtained from humans. Inoculating cattle, 19 resulted in no disease, 9 induced very minimal foci in the prescapular glands after 4 months, 7 resulted in marked disease of the prescapular glands without dissemination, and 4 caused generalized tuberculosis in cattle recipients. Thus, it was impossible to determine the source of a culture by its effects when inoculated into cattle [9]. Descriptions of these early studies are not clear as to whether investigators knew the precise identity of inoculated strains. It is possible that some isolates from humans were not human tubercle bacilli, but were actually M. bovis. Generally, however, conclusions from such comparative studies revealed that bacilli from cattle were more virulent for animals than that obtained from humans [13]. As summarized by Salmon in 1904, "the bovine bacillus, being proved more virulent for all animals upon which it has been tried, is also more virulent for man" [9].

\section{Public Health Concern: Zoonotic Potential and Role of Veterinarians in Early Public Health}

The public health implications of bovine tuberculosis were suggested early by Chauveau, who, beginning in 1865, demonstrated the ability to transmit tuberculosis between cattle through ingestion of diseased material [18]. He reasoned that in man, as well as in animals, transmission of tuberculosis was possible through the consumption of meat or milk from diseased animals.

In 1900, tuberculosis was the leading cause of death in the United States. More than 25\% of all deaths were due to airborne diseases, with tuberculosis being the most important [19]. It is estimated that approximately $10 \%$ of all human tuberculosis cases were the result of exposure to tuberculous cattle or cattle products [20]; more distressing, $25 \%$ of tuberculosis cases in children were caused by $M$. bovis [21]. Rates of bovine tuberculosis were higher in herds housed in close-confinement compared to those found on open pastures, resulting in higher disease prevalence in dairy cattle compared to beef cattle. Bovine tuberculosis was more common in herds close to major cities, since these were often the most limited in pasture and, therefore, utilized more indoor housing. With this consideration, the state veterinarian of Alabama, Charles A. Cary, implemented an "open air clause" to their state program stating: "all dairy cows shall be given each day at least six hours exercise in the open air [22]." Cary was a native of Iowa, but studied in Germany with the most renowned veterinary scientists of the day.

As early as 1885 , there was substantial evidence of the infectiousness of milk from tuberculous cows. Cornell's James Law identified bovine tuberculosis as the most important zoonotic disease of the time [23]. Respected physicians such as Harold C. Ernst preached the dangers of milk from tuberculous cows, especially for children. In 1889, studies conducted by Ernst and veterinarian Austin Peters at the Harvard Medical School bacteriology laboratory, demonstrated that cows affected with tuberculosis in any part of the body could produce milk containing the bacillus, irrespective of the presence or absence of lesions in the udder [23]. An opinion also held by Danish veterinarian Bernard Bang [24]. Although veterinarians were generally in agreement with the conclusions reached by Bang and others, regrettably, Ernst's opinions did not have widespread approval among physicians. A survey in 1890 of 18,000 physicians, showed that many doctors denied the danger of milk as a source of tuberculosis for their patients [7]. Among 1013 physicians responding to the question as to whether they had ever seen a case of tuberculosis that could be traced to consumption of milk, 893 answered "no." Only 11 stated they had seen cases that could be causally linked to consumption of milk [23]. 
Veterinarians, public health officials, and consumers were key to the growing demand for meat and milk free from contamination by tubercle bacilli $[11,13]$. It is estimated that, in 1917 , bovine tuberculosis was responsible for approximately 15,000 deaths in the US; 3-times the number dying from all food-borne illnesses today [25]. Veterinarians understood early the public health concerns of bovine tuberculosis. At a meeting of the United States Veterinary Association in 1887, veterinarians called for increased inspection of dairies and slaughterhouses to reduce the amount of tuberculous meat and milk reaching consumers [26]. As noted by Dr. Cary of Alabama, "if we do not want to eat the stuff ourselves, we had better bury or burn it".

As early as 1899, many important factors in the pathogenesis and epidemiology of bovine tuberculosis were known, or at least hypothesized. Physicians and veterinarians alike established that (1) TB is a contagious disease of cattle propagated by cohabitation of tuberculous and healthy animals, (2) TB could be transmitted by feeding products from infected animals, (3) tubercle bacilli could be visualized microscopically in milk from animals with tuberculosis, but lacking lesions of the udder [11], (4) milk from cows with tuberculosis, but lacking udder lesions could transmit disease orally to guinea pigs, rabbits, pigs, and calves [11], (5) milk from the Boston milk supply could transmit disease to rabbits [11], (6) calves generally acquire infection by feeding on infected milk from tuberculous cows, (7) older cattle generally acquire infection through cohabitation with infected animals, (8) congenital tuberculosis although observed, is rare, (9) animals with widely disseminated disease often show no clinical signs, and (10) animals with either severe or mild disease can shed tubercle bacilli.

At the 1907 annual meeting of the US Association of Livestock Sanitary Boards, state veterinarian of Colorado, Dr. Charles G. Lamb emphasized the need for veterinarians, livestock sanitary boards, and public health officials to work together in the control of contagious disease, especially bovine TB. Citing transmission of TB via milk as an example, Dr. Lamb pointed out the need for a veterinarian on all public health boards. Therefore, the "One Health Concept," prevalent today, which obscures the line between human and animal medicine, has long been recognized as a beneficial strategy for zoonotic disease control.

As early as 1905, the state of Iowa implemented laws stating "that every owner, manager, or operator of a creamery shall before delivering to any person, any skim milk, cause the same to be pasteurized at a temperature of at least 185 degrees Fahrenheit." Addressing the 19th annual meeting (1915) of the US Livestock Sanitary Association, W. B. Barney, a prominent Holstein breeder from Iowa, declared that pasteurization should be made compulsory in the US and should include routine inspections of equipment and appropriate records of operation. However, there was widespread opposition throughout the country stemming from beliefs that pasteurization would increase cost to consumers and heating of milk would destroy nutritional value.

\section{Meat Inspection-Differences in Approach}

Opinions differed between European and American approaches to meat inspection and bovine tuberculosis. In his book, "Handbook of Meat Inspection, 4th ed," German veterinarian, Robert Von Ostertag states: "at present, the view is generally entertained that, in undoubted cases of local tuberculosis, the meat is harmless while in generalized cases it is harmful." Addressing the Royal Commission of 1896, Sir John MacFadyean stated: "I doubt whether there are ten people in this country in the year who contract tuberculosis through meat." In 1894 Europe, the inspection of meat focused on sanitation; animals with diseases not thought contagious to man were considered safe and proper for human consumption. Cattle carcasses affected by bovine pleuropneumonia, foot and mouth disease, or cows in advanced gestation were all used as food. At the same time in the US there was a widespread aversion to eating the meat from animals afflicted with any disease, or in the advanced stages of pregnancy [27]. At the beginning of the 20th century, stewardship of US meat inspection fell upon the BAI. It was the opinion of the BAI that their duty was to protect the consumer from meat which was offensive or repugnant, as well as that which was actually dangerous to public health [27]. Accordingly, inspectors of the BAI were instructed to condemn carcasses from all animals having acute diseases or high fevers, as well as diseases communicable to the consumer and carcasses of periparturient females. Such oversight by the BAI applied only to abattoirs processing meat for international or interstate sale [27]. In 1904, state laws regarding disposition of tuberculous cattle varied from state to state, resulting in confusing and sometimes illogical outcomes. Confusion can be traced to at least 2 relevant, but contradictory, laws, that being livestock sanitary laws that prohibited the use of meat from animals suffering from contagious disease and meat inspection laws that allowed the use of meat from tuberculous cattle with limited disease if diseased portions were trimmed away. In Montana and New Jersey, state regulations prohibited the use of meat from all cattle with contagious disease. Consequently, tuberculous carcasses were to be destroyed [22]. At the same time in Nebraska, meat inspection laws allowed the slaughter of tuberculous cattle if it was felt that the cattle would pass state meat inspection [22]. Complicating the matter was the issue of where the tuberculous cattle would be slaughtered and processed. Many states prohibited shipment of diseased livestock. Inspection of meat by the Federal Government began in 1891, under the direction of the BAI and its chief Salmon [27]. The federal meat inspection act of 1906 [28] by USDA held that "all carcasses affected with tuberculosis and showing emaciation shall be condemned." Although condemnation of all tuberculous carcasses was the call, reality held that carcass disposition was dependent on disease severity [29]. Carcasses with little visible disease were passed for food after removal of diseased portions. Carcasses displaying moderate disease could be rendered into lard or tallow after diseased portions were removed. Severely diseased carcasses were condemned as unfit for food or other 
products [29]. From 1906 to 1916, 1.8\% of cattle slaughtered were retained due to concerns about tuberculosis. In most cases, disease was localized and the affected portions trimmed away, allowing the rest of the carcass to be used for human consumption [25, 28]. However, in 288,000 carcasses disease was so widespread that the entire carcass was condemned and not used for food. Tuberculosis was not the only reason for carcass condemnation; however, it was responsible for condemnation in $68 \%$ of condemnation cases [25].

Although compliance to the 1906 USDA regulation was not complete, the potential condemnation of all carcasses regardless of extent of disease would eventually have two consequences: (1) an urgent need to establish indemnity for producer support and (2) a greater emphasis on eradication as even those animals with moderate disease were deemed unfit for consumption as unrendered products. The first state to implement systematic meat inspection was Alabama, where under the direction of the State Veterinarian, Charles A. Cary, organized inspection began in 1896, in Montgomery, AL. Cary would go on to establish meat and milk ordinances in all of Alabama's major cities. Montana assembled one of the first dairy inspection laws in the country. Under the direction of veterinarian M.E. Knowles, every city in Montana was to have a veterinarian, paid by the state, to inspect dairy cows and their products [22].

A description of the American approach can be found in Connecticut veterinarian Ingram's remarks at the 1917 US Livestock Sanitary Association meeting titled "Municipal Meat Inspection" [30]. Ingram and his fellow veterinarians called for "an inspection to determine if meat comes from an animal with a contagious disease to protect the consumer from dangers from which he cannot protect himself." Ingram went on to describe an attitude still relevant today:

"Currently, federal meat inspection service is limited to meat for interstate or foreign shipment-thus, meat used intrastate is not subject to federal inspection. This responsibility relies on municipal or state inspectors. There is a need to inspect all facilities including smaller, out of the way, slaughterhouses, as these are often objectionable and dangerous to public health. In contrast, central abattoirs afford commercial advantages such as better equipment and options for by-products and are more conveniently inspected. As with Europe, it is preferable for the central abattoirs to be owned by the municipality. State and municipal inspectors should become aware of and follow federal inspection rules, as they are most complete. Advantages of inspectors being veterinarians are that they are aware of animal diseases and potential dangers to human health. The slaughterers should not pay inspectors. Public is suspicious of meat that does not have official stamp of inspection-thus, it fetches a lower price."

\section{Tuberculin: The Foundation for an Eradication Campaign}

In 1890 at a meeting of the International Congress of Medicine in Berlin, Koch announced that he had isolated a substance from tubercle bacilli that could both render guinea pigs refractory to tuberculosis and arrest the disease, even when in an advanced state. As such, Koch was describing his substance as both a preventive and a treatment. He, and others, originally characterized the substance as "paratoloid," a combination of the terms alkaloid and ptomaine (toxic substances released by bacteria) [31]. "Paratoloid" was used as a synonym for "tuberculin" as late as 1901 [32]; however, most physicians and veterinarians knew it as "Koch's lymph." It was soon discredited as both a preventive and a treatment, but Koch had observed that many tuberculous patients injected subcutaneously with tuberculin developed systemic reactions including hyperthermia. Veterinarians recognized these clinical signs as a possible means of detection. Almost immediately, veterinarians in Russia, Denmark, Great Britain, and the US began using Koch's tuberculin to diagnose tuberculosis in cattle. Six months after Koch's announcement of tuberculin, Professor Gutmann of the Veterinary Institute of Dorpat, Russia, used it as a diagnostic aid in cattle $[33,34]$. Professor Eber, a veterinarian from Berlin, was one of the first to summarize the accuracy of the tuberculin test. In 1891, he collected statistics on tested cattle and reported a specificity of approximately $87 \%$ [35]. Prior to the development of the tuberculin test, veterinarians relied on physical examination to diagnose bovine tuberculosis. With limited diagnostic tools, veterinarians only identified one in ten live tuberculous cows [20].

In 1892, Pennsylvania veterinarian, Leonard Pearson, tested a herd of Jersey cattle belonging to Mr. Joseph Gillingham of Claremont Farms. Pearson was assistant professor of veterinary medicine at the University of Pennsylvania and later became Dean of the Veterinary Department of the University of Pennsylvania [36] and Pennsylvania's State Veterinarian. Mr. Gillingham was a trustee of the University [33]. Pearson obtained the tuberculin used in this first test from Europe. A total of 79 animals were tested, 51 of which showed positive reactions to the test. The entire herd was destroyed [7]. This first test in the US was by injection of $0.2-0.4 \mathrm{cc}$ of Koch's tuberculin diluted $1: 9$ in $1 \%$ carbolic acid subcutaneously in the right scapular region [37]. In some infected animals, body temperature increased gradually over $24 \mathrm{hrs}$ whereas in others body temperature did not begin to rise until $20 \mathrm{hrs}$ after injection. Still, in other animals, body temperature rose dramatically at $10 \mathrm{hrs}$, and then declined by $12 \mathrm{hrs}$. This variability in change in temperature foreshadowed difficulties associated with this particular application of the test. This first wholeherd test drew much attention and much criticism. Many noted veterinarians of the day, Dr. Samuel Dixon of the Academy of Natural Science in Philadelphia, and Dr. W.L. Zuill, professor of veterinary surgery at the University of Pennsylvania, were decidedly opposed to tuberculin as a means of diagnosis of bovine tuberculosis, believing it toxic and harmful [33]. Dr. Zuill headed a special commission to 
investigate tuberculin's "curative, preventive, and diagnostic properties" [7]. Dr. Dixon remarked to Mr. Gillingham, prior to testing of his prized Jersey herd, that he (Gillingham) was foolish to sacrifice so many valuable animals and that Dr. Pearson was nothing but an enthusiastic dreamer [33]. Pearson on the other hand confidently declared the testing a complete success and commended Gillingham for his broad-mindedness, stating that this event was a step to the passage of laws relating to tuberculosis and Gillingham's sacrifice would come to be a blessing to every cattle breeder and consumer of cattle products in the US [33]. This historic test was followed by testing of herds belonging to agricultural colleges and experiment stations in Maine, New Jersey, Wisconsin, and Vermont. Dr. Pearson went on to test some of the best herds in America from 1892 to 1895 . In 1893, veterinarian E. C. Schroeder conducted the first official test for the BAI, testing a herd of 34 cattle near New Charlotte, NY. Fifteen animals showed positive reactions. Thirteen of the fifteen had typical lesions of tuberculosis upon postmortem examination [38].

Tests were voluntary, at the expense of the farmer, and no indemnity was paid for slaughtered reactors, which were buried. Pearson soon developed a plan to have reactors appraised, killed under official supervision, and the meat, if considered suitable, used for food [33]. Key elements of this plan were eventually adopted throughout the US. Education of livestock owners by veterinarians was an important factor. The efficacy of tuberculin testing was not difficult to demonstrate, since many reactors were necropsied on the farms where they were tested. These necropsies drew large, sometimes antagonistic audiences; however, veterinarians were able to demonstrate tuberculous lesions in most animals. After such displays, once skeptical onlookers were some of the first to request testing of their herds [39]. In other cases, owners of reactor animals were encouraged to follow the animals to market and, with the local veterinarian, observe the postmortem examination after slaughter [40]. Education of the public concerning bovine tuberculosis was listed as one obstacle to disease eradication [41]. Presenting information in a manner understandable to the layman and possessing a thorough knowledge of the subject, specifically sciencebased information, were areas identified for improvement [42]. The goal of early 20th century veterinarians to educate the public was best summarized by D. F. Luckey, State Veterinarian of Missouri and President of the US Livestock Sanitary Association in 1907, "it is said that the highest end of education is to bring the general public to the point where it can appreciate the scientific work and know whose advice to follow [43]."

In the infancy of tuberculin testing, many cattlemen objected to the tuberculin test, alleging it was inaccurate and induced disease or caused abortion [13]. Initially, tuberculin was administered subcutaneously and required monitoring of the animal for a rise in body temperature. This necessitated the veterinarian to make several preinjection temperature measurements as well as regular measurements for $24 \mathrm{hrs}$ after injection [18], limiting the number of animals that could be examined by a single veterinarian in any given day. During is early use very little in tuberculin testing practice was standardized. Several methods of tuberculin administration were practiced, including the subcutaneous, ophthalmic, intrapalpebral, and intradermal [44]. In some cases, more than one method was used on the same animal [45]. Tuberculin from Germany was commercially available; however, this tuberculin was 10 -fold stronger than tuberculin distributed free of charge by the USDA's BAI. In 1910, State Veterinarian of New York, Veranus A. Moore, believed detection of cattle in the early stages of disease, through tuberculin testing, was not necessary and that veterinarians should use physical exam to determine the high shedders, which he deemed most important for removal [46]. Moore believed the US approach to tuberculosis eradication was too harsh, considering the chronic nature of the disease. Dr. Moore insisted that the control of the disease should be in the hands of the owner, not the government. Others, such as prominent supporter of the dairy industry, and former Governor of Wisconsin (1889-1891), William D. Hoard championed the use of the tuberculin test to eradicate bovine tuberculosis. Cows at his own dairy farm were routinely tested with tuberculin. He attributed the tuberculosis-free status of his herd to regular tuberculin testing, slaughter of test positive cattle, and rigorous quarantine and testing of all introductions to the herd [47]. Many dairy farmers did not share this opinion. Hoard's 45-year campaign for tuberculin testing cost his magazine, Hoard's Dairymen, thousands of subscriptions and significant lost revenue.

Numerous rumors and misconceptions circulated concerning the test; however, the most ardent objection was that the test was inaccurate. Others feared that such a program would decimate the cattle population and lead to shortages of milk and meat [48]. Bills to ban the tuberculin test were debated in state legislatures [49]. Cases concerning tuberculin testing of cattle reached Supreme Courts of Minnesota, Nebraska, Michigan, Ohio, Washington, Illinois, California, and Iowa [50]. The Iowa Supreme Court considered a case from Mitchell County where the plaintiffs declared that the tuberculin test was, in fact, not a test because accuracy and dependability were lacking. As proof they cited cases where healthy cows tested positive for tuberculosis and tuberculous cows tested negative. The Iowa Supreme Court; however, upheld the constitutionality and legitimacy of tuberculin test stating, "... careful reading of the evidence produced convinces us that the test is reliable, useful, and advantageous" [51].

This, among other factors, led to what is known as the "Iowa Cow War." In 1931, in Tipton, Iowa, hundreds of farmers, opposed to compulsory testing, confronted state veterinarians and sheriffs sent to test herds owned by W.C. Butterbrodt and E.C. Mitchell. Farmers blocked roads, threatened veterinarians, and splattered them with eggs, water, and feces. Less than 2 weeks later veterinarians and sheriffs arrived at the farm of Jake Lenker to be met by a force of more than 200 farmers, many of whom immediately doused the veterinarians with water, mud, and rotten eggs. Iowa State Veterinarian, Peter Malcom, was one of the last to escape the mob, but not before the gas line of his car was broken, radiator filled with mud, windows smashed, and tires punctured with pitchforks $[50,52]$. Unmoved, 
Malcom said he would test every cow in Cedar County. In response to the unrest, enraged Iowa Governor Daniel Turner imposed martial law, and the next day over 1800 national guardsmen arrived in Tipton, exiting the train to march through crowds of angry protesters. The guardsmen were there to protect veterinarians and ensure that testing continued. Accompanied by armed guardsmen, veterinarians returned to Lenker's farm only to find the cattle gone. Lenker had sold his cattle rather than submit to testing. Lenker was arrested and arraigned for contempt of court and released under $\$ 10,000$ bond. National Guard troops remained in Tipton for 2 months [50].

Between 1892 and 1915, as veterinarians became more accustomed to the use of tuberculin, methods began to vary dramatically. As noted in 1915 by New York State Veterinarian John G. Wills, "when tuberculin first came into use, the procedure employed was somewhat more exacting and in some respects more scientific than was later observed after it had become a more familiar agent" [45]. By 1915, the number of temperature readings, before and after tuberculin administration, had been reduced [41]. In 1915, at a meeting of the Livestock Sanitary Association, Wisconsin State Veterinarian, O. E. Eliason lamented that "the value of the test depended too much on the ability, competency, and experience of the examiner" [45]. Standard procedures and official oversight of tuberculin testing were needed. In spite of these limitations, use of the subcutaneous tuberculin test, in a test and slaughter program, reduced disease prevalence in the District of Columbia from $18.87 \%$ in 1909 to $0.84 \%$ in 1918 . In human medicine in 1908, Charles Mantoux, expanding on work by Clemens Freiherr von Pirquet, developed the intracutaneous (intradermal) tuberculin test. By 1921, the intradermal method of tuberculin testing became the official method approved by the BAI $[38,53]$. Tuberculin testing would impact farms in every state and county. Between 1917 and 1940 veterinarians administered over 232 million tuberculin tests, resulting in the destruction of 3.8 million cattle. [20].

\section{Plugging the Test}

Among other idiosyncrasies, administration of the tuberculin test could render an animal unresponsive to subsequent tests for up to 8 weeks. Early on, it was recognized that animals might need to be retested due to equivocal reactions. The elapsed time between the initial test and retest was unsettled; being set at widely different periods by various authorities [37]. To provide guidance, livestock sanitary boards conducted experiments to determine the optimal time between testing. Guidelines of 1912 recommended a 4 to 7 day interval with the retest tuberculin being 3-times the strength of tuberculin used in the initial test. Theory held that the initial injection of tuberculin desensitized the animal to make them less receptive to the retest. Current recommendations do not allow retesting for 60 days, and USDA accredited veterinarians must conduct the test [54]. However, during the early 1900s, livestock owners could test their herd privately and sell reactors to unsuspecting buyers. Retesting by the new buyer would result in a negative test. For all practical purposes, healthy cattle could not be differentiated from diseased cattle. This practice was known as "plugging the test," and unscrupulous cattle buyers specialized in this practice. One of the worst offenders was likely the leading cattle dealer in the US, James Dorsey of Gilberts, IL, who was credited with creating 10,000 new foci of bovine tuberculosis across the US, Canada, and Mexico through the practice of plugging the test. $[20,25]$. The actions of Dorsey, and other disreputable cattle buyers, created not only a public health predicament, exposing thousands of families to tuberculous cattle and cattle products such as raw milk, but also created hardships for fellow cattlemen when many states refused shipments of Illinois cattle, or introduced tuberculosis into their own herds through purchase of infected animals [25]. By 1914, at least 12 states refused to accept cattle from Illinois, except under certificate of federal inspection. Dorsey was finally indicted in 1915, after selling diseased cattle for over 10 years. Dorsey was sentenced to 8 years in a federal penitentiary. It is estimated that Dorsey was responsible for thousands of cases of human tuberculosis, in comparison to the 47 cases of typhoid fever ascribed to the epitome of contagion transmission, "Typhoid Mary" [25]. Dorsey had become quite wealthy after years of fraudulent dealings, and it could be argued that Dorsey's money and influence extended into the political arena. In 1920, after serving only half of an 8year sentence, Dorsey was pardoned by President Woodrow Wilson [25].

Unfortunately, dishonest veterinarians also practiced deception. Some veterinarians invented mixtures, including antipyretics, that when given to the animal shortly before tuberculin testing, would prevent a rise in temperature [55]. Other dishonorable veterinarians, issued certificates stating the animal had not reacted to tuberculin, without ever conducting the test [56]. By 1914, in large part due to the influences of James Dorsey, railroad companies were warned not to accept health certificates from Illinois veterinarians, except those from a federal veterinarian or a certificate certified and signed by O. E. Dyson, State Veterinarian of Illinois [25]. Deception was so widespread and severe, other states barred, or discouraged, reputable veterinarians from traveling to Illinois to administer tuberculin tests.

\section{Controversy over Different Models of Tuberculosis Control}

From the outset, there was controversy over the system for control of bovine TB. Danish veterinarian Bernard Bang proposed a control model without slaughter, that was appealing to producers, as it prevented loss of critical genetic resources [22]. In Bang's model, farmers were encouraged to segregate their cattle into two herds: animals that reacted to tuberculin and those that showed no reaction to tuberculin and were thus considered healthy. Each herd was under the control of separate handlers and housed in separate stables. Calves were to be removed at birth and milk from the dam pasteurized before use. Slaughter of animals from the subherd could only be done under supervision of a competent meat inspector. With this system, the healthy 
herd progressively increased in size whereas the tuberculous herd slowly diminished. The healthy herd was continually monitored through tuberculin testing to detect latent or recently infected animals. Such practices would minimize disease spread within a herd through contaminated feed, water, bedding, sputum, feces, and through aerosols of such materials. In many herds, however, tuberculosis was introduced by attempts to improve herd genetics through the importation of superior breeding stock. While Bang's model was widely used in Europe, it was less popular within the US. Initially attractive to owners of expensive breeding animals, the cost of maintaining a subherd was prohibitive for many. Extra time and expense involved in caring for reactors, as well as poor public acceptance of pasteurized milk were major deterrents. As stated by Illinois veterinarian, Dr. Charles P. Lovejoy,

\begin{abstract}
"In four different instances, I advised the owner of the herd to isolate his reacting cattle and breed them out. In each and every case, I was asked to go and kill them. Bad news spreads very quickly. These men said they might as well kill their whole herd as to have isolated cattle, after it had become known that the disease existed" [22].
\end{abstract}

This sentiment was common; thus, most state/territory veterinarians favored a "test and remove" approach and rarely applied Bang's model.

The test and remove approach was not without difficulties and controversy. Primary problems were the issues of indemnity, product use, and quarantine [22]. According to a 1906 regulation, carcasses of animals suffering from any contagious disease were to be destroyed or buried. In practice, however, diseased portions were trimmed away and the remainder of the carcass used for food. In cases of disseminated disease, the entire carcass was destroyed and not used for human consumption. Some cattle suspected of failing inspection would be sold to buyers that would route them to uninspected plants. If suspicious meat was sold, the reputation of the owner, butcher, and veterinarian (including regulatory veterinarians) were at stake. To circumvent this consequence, reactor cattle were shipped to distant public abattoirs such as Chicago, decreasing the possibility that local citizens would become aware of the presence of tuberculosis in a given herd [22].

In 1904, the President of the US Livestock Sanitary Association and Arizona territorial veterinarian, J. C. Norton stated, "a rule requiring a certificate of tuberculin test to accompany interstate shipment would greatly assist state veterinarians in their work to encourage further testing and would prevent the creation of new centers of infection." By 1909, 24 states had enacted tuberculin test barriers for entry of cattle into their states with varying stringency and timing related to date of shipment. However, application of the test varied tremendously from state to state. S. H. Ward, state veterinarian of Minnesota noted:

"It does not require any extended argument to convince us that the question to be discussed is the necessity for some uniformity" ... "let regulations be drawn up by the Bureau of Animal Industry."

Dr. Alonzo D. Melvin, BAI chief, responded in favor, noting the immense undertaking necessary and the current lack of funds and personnel to implement such a plan. Regardless, there was a sentiment that oversight and control of tuberculin testing for interstate shipment of cattle be transferred from the states to the BAI.

In 1883, a veterinary division was created within USDA. The division was assigned a 7-acre plot of land outside Washington, DC, on which they were to conduct research [38]. Progress was made in 1884 when the BAI was formed by congressional mandate to "prevent the exportation of diseased cattle, and to provide means for the suppression and extirpation of bovine pleuropneumonia and other contagious diseases [5]." The BAI was placed under the management of it's first chief, Daniel E. Salmon [22]. Power was given to the Secretary of Agriculture to condemn animals capable of spreading disease across state lines [20]. Salmon surrounded himself with capable, forward thinking scientists such as physician, pathologist Theobald Smith (1884) and veterinarians, Fred L. Kilbourne (1885), Cooper Curtice (1886), Veranus Moore (1886), and E. C. Schroeder [38]. Fueled by success in eradicating bovine pleuropneumonia, officials would find tuberculosis to be a more formidable and widespread challenge. By 1900, the BAI was requiring tuberculin testing of all cattle imported into the US from foreign countries. Beginning in 1906, the Pathological Division and Experiment Station of the BAI, now under the direction of veterinarian Alonzo D. Melvin, conducted research on establishing tuberculosis free herds through the process of test and removal. Herds in Maryland, Virginia, and the District of Columbia were annually tested over a period of 12 years. Over 17,000 cattle were tested; the prevalence of positive reactors decreased from $18.87 \%$ to $0.17 \%$. Epidemiological investigations, by the BAI, revealed that most reactors after 1917 were the result of cattle movement, animals introduced into the study herds from outside tuberculous herds. Not until 1919 did Congress appropriate the first federal funds specifically targeted to investigate the cause, mode of spread, treatment, and prevention of bovine tuberculosis [36].

Under the leadership of veterinarians such as Daniel. E. Salmon (1884-1905), Alonzo D. Melvin (1905-1917), John R. Mohler (1917-1943), Arthur W. Miller (1843-1945), and Bennett T. Sims (1945-1954), veterinarians, and other scientists, employed by the BAI conducted basic and applied research in the years before and after the establishment of a national program in 1917, Interestingly, Dr. Melvin died, while still BAI chief, in 1917 of tuberculosis that had been diagnosed by Dr. Mohler some 16 years earlier [38]. Noteworthy research included differentiation between bovine and human tubercle bacilli, differential virulence of the bovine and human tubercle bacilli in cattle $[9,57]$, morphological and biochemical differences in cultures of human and bovine tubercle bacilli $[9,57]$, transmissibility of bovine tubercle bacilli from cattle to swine [58], immunization of cattle to prevent tuberculosis [59], tuberculin potency testing, 
alternative routes of tuberculin administration $[53,59]$, and use of test and remove methods to remove tuberculosis from a herd.

\section{State's Role in Eradication Program}

Pennsylvania was one of the first states to establish a coordinated, organized effort to repress bovine tuberculosis [13]. At the turn of the century, Pennsylvania was home to 6 million people and 2 million cattle. The statewide estimated prevalence of bovine tuberculosis was 2-3\%; however, there were herds with 30 to $100 \%$ of animals infected. In 1895, the Pennsylvania State Livestock Sanitary Board was created, composed of the Governor, Secretary of Agriculture, Dairy and Food Commissioner, and State Veterinarian. The board was free to create and enforce its own rules and regulations. Initial funding of $\$ 40,000 / \mathrm{yr}$ was used to address tuberculosis, anthrax, glanders, and rabies. Money was also available for the state to produce its own tuberculin and anthrax vaccines. The program began with herd owners voluntarily making application for their herd to be tested. Owners were asked to provide reasons why they desired their herd to be tested. Obviously, owners most interested in creating and maintaining a herd free of tuberculosis were first to enter the program. Test-positive animals were either euthanized and indemnity paid based on appraisal, or reacting animals could be quarantined as a sub herd and cared for apart from the rest of the herd (Bangs model of tuberculosis control). The owner agreed to disinfect the premises, and correct any other conditions in order to keep his herd free of tuberculosis. An interesting feature of the early Pennsylvania program was a concerted effort in public education. In regions where reactors were identified, circulars and articles in agricultural reports were distributed. Efforts were made to euthanize and examine reactors in the same region where they were identified; thereby, interested parties could see lesions of tuberculosis. By 1899, over 33,000 cattle had been tested with $13.7 \%$ testing positive for tuberculosis. Indemnity payments totaled $\$ 102,909$, an average of $\$ 22.56 /$ head. In 1898 , a requirement that all cattle entering Pennsylvania be tested was added to the program. The program was well received by Pennsylvania producers and many more applications for testing were received than could be handled with available funding. In addition to strong public support, support from organized producer groups and the involvement of the state's many practicing veterinarians were identified as factors for success.

Massachusetts was also an early participant in tuberculosis eradication [56]. However, different laws were passed in $1892,1894,1895$, and 1896 resulting in confusion over which program was in effect in a given situation [7]. The potential for success in Massachusetts was severely impeded when the State Legislature passed a law restricting the use of tuberculin to confirmation of a diagnosis made by physical exam [7]. Such a law prevented the systematic and widespread testing of all herds crucial to the success in other states. Recognizing the inadequacy of such a program, neighboring Maine refused to accept cattle from Massachusetts that were deemed to be tuberculosis-free by physical exam only [56]

\section{Conception of a National Eradication Program}

At an 1884 meeting of livestock sanitary officials, a committee with representatives from 8 states and the BAI recommended the formation of the US Livestock Sanitary Association, later known as the US Animal Health Association (USAHA). The first formal meeting was held in Fort Worth, Texas, in 1897. Attendees included representatives from state and territorial sanitary boards, state and territorial veterinarians, and five delegates named by the US Secretary of Agriculture. By the thrid annual meeting of the US Livestock Sanitary Association, held in 1899, bovine tuberculosis was widely discussed-surpassing "Texas Fever" as the major topic. Attendees observed postmortems on cattle that reacted to the still controversial tuberculin test. A resolution was passed recognizing that bovine $\mathrm{TB}$ is a contagious disease that was spreading, use of tuberculin was the best means for recognizing the disease in live animals, and states should authorize methods to control it. Bureau Chief Salmon pledged that the USDA would follow the recommendations set forth by the US Livestock Sanitary Association; thereby, laying the ground work for a close working relationship between sanitary boards, state veterinarians, and federal veterinarians and establishing a role for the US Livestock Sanitary Association (USAHA) in guiding federal government on establishing and implementing livestock disease regulatory programs. At the eighth annual meeting of the US Livestock Sanitary Association in 1904, a special committee was formed to (1) deal with TB vigorously, (2) determine the reliability of the tuberculin test, (3) determine methods of disposing of infected animals, and (4) and define rules governing interstate shipment of dairy cattle and infected cattle for slaughter. This special committee was the basis for the current USAHA committee on bovine tuberculosis, again demonstrating the role for state and local veterinarians in conception and implementation of a federal eradication program still in use today. By 1921, the committee on tuberculosis divided is efforts into 7 categories, which are still applicable today: education, state-federal cooperation, regulations, administration, prevention, public health, and finances [60].

A milestone in the eradication program was the notion of accredited herds [61], a concept that remains relevant today. A special committee composed of five state and federal veterinarians, and 5 representatives from livestock breeder associations developed the original plan. A proposal outlining requirements of accredited herds was unanimously adopted at the 1917 meeting of the US Livestock Sanitary Association [62]. Accredited herds would receive a certificate of accreditation from the relevant state authority, and the BAI. The certificate was valid for 1 year. The certificate declared that tuberculosis had not been present within the herd for 2 years. Under certification cattle could be shipped interstate from accredited herds with no further tuberculin testing. In return, producers agreed to regular tuberculin testing of the entire herd as well as accurate and complete animal identification practices [61, 62]. In 1917, there were no accredited herds in the US, but by 1927 there were over 
96,000 accredited herds comprising 1.5 million cattle with an additional 1.3 million herds having been tested once in the process of accreditation [63].

Having observed success in various states, the BAI, under the direction of Melvin, obtained funds ( $\$ 75,000$, equivalent to $\sim \$ 1.27$ million in 2010) from congress in 1917 to create the Tuberculosis Eradication Division headed by Tennessee veterinarian John A. Kiernan. In late 1917, at a meeting of the US Livestock Sanitary Association, the first Uniform Methods and Rules (UM \& R) for tuberculosis-free herds was approved [36]. Sixty days after the adoption of the UM $\& \mathrm{R}$, the first tuberculosis-free herd was accredited under the new guidelines. The herd was owned by the US Soldiers Home in Washington, DC. By 1921, eradication field offices were established in 46 states [36]. Such offices were created and operated with cooperation from state livestock sanitary boards. Motivated by a desire not to place state and federal veterinarians in direct competition with local veterinarians, as well as a critical need for more veterinarians able to conduct tuberculin testing, the accredited veterinarian program was established in 1918 [64]. This allowed private practitioners, subject to a practical exam administered by the BAI, to conduct tuberculin testing. The idea stemmed from a similar program administered by the BAI to test horses for various diseases prior to export to Canada. That program consisted of 63 practitioners in 12 different states. By the close of 1920, there were over 5500 veterinarians accredited by the BAI to assist with cattle testing for tuberculosis. With assistance from practitioners, the testing phase of the program exploded. In 1901, approximately 200,000 animals were tested, and the prevalence of positive reactors ranged from $3.9 \%$ to $100 \%$ depending on region; bovine tuberculosis was more common in northeastern and north central states where dairy cattle were more common than in western states where beef cattle predominated [36]. On average, in 1917, $5 \%$ of US cattle were tuberculous, including $10 \%$ of dairy cattle and 1-2\% of beef cattle [25]. By 1935, 25 million cattle were tested with a disease prevalence of $1.5 \%$ [21]. From 1917 to 1941, almost 25,000,000 cattle were tested for bovine tuberculosis. The percent reactors removed from herds declined from $4.9 \%$ in 1918 to $0.3 \%$ in 1941. This led Secretary of Agriculture, Claude R. Wickard, to declare, "the United States is now practically free of bovine tuberculosis" [65] as every county in the country had reached the modified accredited status $(<0.5$ per cent of animals tested that react positively). The 23-year cost to taxpayers was $\sim \$ 200,000,000$ plus the cost to farmers [65]. Secretary Wickard's statement in 1941 was in stark contrast to the 1917 statement, by Henry Wallace (Secretary of Agriculture 1933-1940), that eradication of tuberculosis seemed an "impossible undertaking" [20].

Progress in tuberculosis eradication in the US was relatively rapid compared to that seen in parts of Europe. Bovine tuberculosis has never been as prevalent in the US as it has been in parts of Europe, and although it is tempting to compare the programs and rate of progress between countries, there are significant differences that make such comparisons problematic. In the early 1900s, the prevalence of disease in the US was significant, but relatively low at approximately 5\%. By 1941, every county in the US had a prevalence $<0.5 \%$ and was considered accredited free of bovine tuberculosis [20]. Reducing the prevalence to levels below $0.5 \%$ was achievable at a relatively low cost [20]. The prevalence rate in Europe during this same period was much higher $(25-80 \%)$ thus decreasing by $4.5 \%$ would have made little difference in the overall prevalence and decreasing to a level below $0.5 \%$ would have required the slaughter of enough cattle to create food shortages [20]. Fear of negative public perception and food shortages contributed to the less aggressive approaches adopted by most European countries compared to that of the US and BAI. Even Bernard Bang advocated a less aggressive approach, fearing food shortages more than contaminated meat and milk. In view of these sentiments, it was not until 1945 that most European countries imposed mandatory test and slaughter programs as well as compulsory milk pasteurization [20]. Regardless, the effective and relatively rapid diminution in disease prevalence in the US is generally attributed to the stringent application of the test and slaughter method of control. Between 1917 and 1945, there were 3,891,950 tuberculin reactors slaughtered at a cost of $\$ 250,000,000$ to the federal, state, and local governments involved [66].

\section{Conclusions}

Veterinarians, and others, that completed the "impossible undertaking" of establishing the US bovine tuberculosis eradication program should be proud of their efforts. Those efforts range from the early pioneers in infectious disease research to the many accredited private practitioners that administer thousands of caudal fold tests every day. At the inception of the eradication program, policy decisions often arose from argumentative conversations in open forums between livestock producers, state and local veterinarians, federal and public health officials, as well as many others. On the surface, it appears as an undirected and unorganized affair; however, it led to a formal process for input and debate, still in use today as exemplified by the USAHA annual meetings. The result has been to decrease disease prevalence from 5\% in 1917 to approximately $0.001 \%$ today [67]. Although eradication has not yet been achieved, the program has seen a steady decline in prevalence, decreasing by $90 \%$ every 20 years [68]. Early efforts focused on eliminating tuberculosis from breeding stock and providing uninfected animals for replacements. Federal funding for bovine TB efforts increased from $\$ 75,000$ in 1917 to $\$ 500,000$ in 1918 and to $\$ 1.5$ million in 1919 [20]. State spending on eradication also increased from $\$ 2$ million in 1918 to $\$ 13$ million in 1927. In the first 2 decades of the program, state funding outpaced federal funding $2: 1$. As the federal government made available emergency funding in the mid1930s, state funding decreased to half of federal funding [20].

The USDA estimated the cost of the program to livestock producers, at the onset was approximately $\$ 40$ million annually [20]. It is estimated that over the period 1917 to 1962 , the cost of the program was $\$ 258$ million in 
1918 dollars and \$3 billion in 2003 dollars [20]. Annual benefits during this same time period are estimated at $\$ 98.7$ million per year, equivalent to 12-times the annual costs [20]. Costs and benefits of the eradication program can also be viewed from the perspective of public health and disease prevention. The effort to eradicate bovine tuberculosis resulted in a significant decrease in human tuberculosis due to Mycobacterium bovis. It is estimated that the eradication program, combined with pasteurization of milk, prevented over 25,000 deaths annually [20]. Other analyses, focused on the livestock sector suggest that during the first years of the program costs may have outweighed benefits; however, benefits have consistently outweighed costs for the majority of the campaign [68]. As a whole, net annual benefits of the program are approximated at $\$ 159$ million; the program returning over $\$ 13$ billion to the economy since its conception [68].

\section{References}

[1] V. A. Moore, "Bovine tuberculosis, its problems and control," in Proceedings of the 15th Annual Meeting of the United States Livestock Sanitary Association, pp. 51-56, Chicago, Ill, USA, 1911.

[2] K. A. Alexander, P. N. Laver, A. L. Michel et al., "Novel Mycobacterium tuberculosis complex pathogen, M. mungi," Emerging Infectious Diseases, vol. 16, pp. 1296-1299, 2010.

[3] N. H. Smith, R. G. Hewinson, K. Kremer, R. Brosch, and S. V. Gordon, "Myths and misconceptions: the origin and evolution of Mycobacterium tuberculosis," Nature Reviews Microbiology, vol. 7, no. 7, pp. 537-544, 2009.

[4] B. M. Rothschild, L. D. Martin, G. Lev et al., "Mycobacterium tuberculosis complex DNA from an extinct bison dated 17,000 years before the present," Clinical Infectious Diseases, vol. 33, no. 3, pp. 305-311, 2001.

[5] G. Diamant, "Regulatory veterinary medicine: and they blew a horn in Judea," Journal of the American Veterinary Medical Association, vol. 172, no. 1, pp. 45-54, 1978.

[6] L. Cobbett, "The relation between animal and human tuberculosis," in The Causes of Tuberculosis, Cambridge Public Health, pp. 185-195, Cambridge University Press, 1917.

[7] E. B. Miller, "Tuberculous cattle problem in the United States," Historia Medicinae Veterinariae, vol. 14, no. 1-2, pp. 1-64, 1989.

[8] M. P. Ravenel, "Three cases of tuberculosis of the skin due to inoculation with bovine tubercle bacillus," Philadelphia Medical Journal, vol. 6, pp. 125-126, 1900.

[9] D. E. Salmon, Bovine Tuberculosis and Public Health, United States Department of Agriculture, 1904.

[10] L. Shrady and G. F. Stedman, "Human and bovine tuberculosis," Medical Record and Weekly Journal of Medicine and Surgery, 1902.

[11] H. C. Ernst, Infectiousness of Milk: Result of Investigations Made for the Trustees of the Massachusetts Society for Promoting Agriculture, The Riverside Press, Cambridge, Mass, USA, 1895.

[12] C. E. Dolman, "Theobald Smith, 1859-1934: a fiftieth anniversary tribute," ASM News, vol. 50, pp. 577-580, 1984.

[13] L. Pearson, "The Pennsylvania plan for controlling tuberculosis of cattle," in Proceedings of the American Veterinary Medical Association, W. L. Williams, Ed., pp. 161-182, American Veterinary Medical Association, Ithaca, NY, USA, 1899.
[14] D. C. Lochead, "Transmissibility of bovine tuberculosis to the human," in Proceedings of the 32nd Annual Meeting of the United States Livestock Sanitary Association, pp. 526-547, Chicago, Ill, USA, 1928.

[15] A. D. Melvin, "Tuberculosis-summary of methods and results to date," in Proceedings of the 15th Annual Meeting of the United States Livestock Sanitary Association, pp. 76-79, Chicago, Ill, USA, 1911.

[16] D. E. Salmon, Report of the Committee on Animal Diseases and Animal Food, American Public Health Association, New Orleans, La, USA, 1902.

[17] A. J. Lartigau, "A study of the variation in virulence of the bacillus tuberculosis in man," Journal of Medical Research, vol. 62, pp. 152-162, 1901.

[18] L. Pearson and M. P. Pearson, Eds., Tuberculosis of Cattle and the Pennsylvania Plan for Its Repression, Commonwealth of Pennsylvania Department of Agriculture, Harrisburg, Pa, USA, 1901.

[19] E. M. Crimmins and G. A. Condran, "Mortality variation in U.S. cities in 1900: a two-level explanation by cause of death and underlying factors," Social Science History, vol. 7, no. 1, pp. 31-60, 1983.

[20] A. L. Olmstead and P. W. Rhode, "An impossible undertaking: the eradication of bovine tuberculosis in the United States," Journal of Economic History, vol. 64, no. 3, pp. 734-772, 2004.

[21] J. D. Roswurm and A. F. Ranney, "Sharpening the attack on bovine tuberculosis," American Journal of Public Health, vol. 63, no. 10, pp. 884-886, 1973.

[22] J. C. Norton, "President's annual address," in Proceedings of the 7th Annual Meeting of the Interstate Association of Livestock Sanitary Boards, pp. 7-35, St. Louis, Mo, USA, 1904.

[23] B. G. Rosenkrantz, "The trouble with bovine tuberculosis," Bulletin of the History of Medicine, vol. 59, no. 2, pp. 155-175, 1985.

[24] "The British Congress on Tuberculosis," Journal of American Medical Association, vol. 37, no. 6, pp. 387-388, 1901.

[25] A. L. Olmstead and P. W. Rhode, "The Tuberculous cattle trust: disease contagion in an era of regulatory uncertainty," Journal of Economic History, vol. 64, no. 4, pp. 929-963, 2004.

[26] R. A. Packer, "Veterinarians challenge Dr. Robert Koch regarding bovine tuberculosis and public health," Journal of the American Veterinary Medical Association, vol. 196, no. 4, pp. 574-575, 1990.

[27] D. E. Salmon, “The federal meat inspection," in Yearbook of Agriculture, pp. 67-80, Government Printing Office, Washington, DC, USA, 1894.

[28] G. Ditewig, "Meat inspection service of the United States Department of Agriculture," in Yearbook of Agriculture, pp. 7197, Government Printing Office, Washington, DC, USA, 1916.

[29] A. D. Melvin, "The economic importance of tuberculosis of food-producing animals," in The 25th Annual Report of the Bureau of Animal Industry for the Year 1908, pp. 97-107, Bureau of Animal Industry, Washington, DC, USA, 1910.

[30] F. A. Ingram, "Municipal meat inspection," in Proceedings of the 20th Annual Meeting of the United States Livestock Sanitary Association, pp. 191-195, Chicago, Ill, USA, 1916.

[31] H. C. Ernst, Koch's Treatment of Tuberculosis, Damrell and Upham Publishers, Boston, Mass, USA, 1891.

[32] G. M. Gould, The Practitioner's Medical Dictionary, P. Blakiston's Son and Co., Philadelphia, Pa, USA, 2nd edition, 1910.

[33] C. J. Marshall, "Progress in controlling bovine tuberculosis," Journal of the American Medical Association, vol. 80, pp. 625633, 1932. 
[34] C. J. Marshall, "Tuberculin test and retest," Journal of the American Medical Association, vol. 5, pp. 308-337, 1917.

[35] R. Carswell, "Value of the negative subcutaneous tuberculin test," The British Medical Journal, vol. 1, pp. 990-992, 1936.

[36] U. G. Houck, The Bureau of Animal Industry of the United States Department of Agriculture: Its Establishment, Achievements and Current Activities, Hayworth Printing Company, Washington, DC, USA, 1924.

[37] C. H. Higgins, "Channels of infection and localization in tuberculosis," Journal of the American Medical Association, vol. 52, pp. 299-308, 1917.

[38] O. H. V. Stalheim and W. M. Moulton,, "Part II: veterinary medicine in the United States department of agriculture," in 100 Years of Animal Health 1884-1984, V. Wiser, L. Mark, and H. G. Purchase, Eds., pp. 19-62, Associates of the National Agricultural Library, Beltsville, Md, USA, 1986.

[39] A. J. Glover, "Methods of popular education in an antituberculosis campaign," in Proceedings of the 15th Annual Meeting of the United States Livestock Sanitary Association, pp. 42-47, Chicago, Ill, USA, 1911.

[40] E. Z. Russell, "Bovine tuberculosis," in Proceedings of the 21st Annual Meeting of the United States Livestock Sanitary Association, pp. 20-26, Chicago, Ill, USA, 1917.

[41] D. F. Luckey, "Obstacles in the way of controlling tuberculosis of cattle," in Proceedings of the 10th Annual Meeting of the Interstate Association of Livestock Sanitary Boards, pp. 31-47, Springfield, Ill, USA, 1906.

[42] T. Butler, "The value of farmer's institutes in educating the public on contagious diseases of livestock," in Proceedings of the 10th Annual Meeting of the Interstate Association of Livestock Sanitary Boards, pp. 56-59, Springfield, Ill, USA, 1906.

[43] D. F. Luckey, "President's annual address," in Proceedings of the 11th Annual Meeting of the Interstate Association of Livestock Sanitary Boards, pp. 7-11, Richmond, Va, USA, 1907.

[44] K. F. Meyer, "Newer methods of tuberculin testing," in Proceedings of the 14th Annual Meeting of the United States Sanitary Livestock Association, pp. 56-62, Chicago, Ill, USA, 1910.

[45] J. G. Wills, "How should a tuberculin test be applied to insure accuracy in results?" in Proceedings of the 20th Annual Meeting of the United States Livestock Sanitary Association, pp. 132-137, Chicago, Ill, USA, 1916.

[46] W. A. Evans, "Sanitary milk supply for cities and towns from a health commissioners standpoint," in Proceedings of the 14th Annual Meeting of the United States Livestock Sanitary Association, pp. 1115-1118, Chicago, Ill, USA, 1910.

[47] W. D. Hoard, “Tuberculosis control from a laymen's standpoint," in Proceedings of the 14th Annual Meeting of the United States Livestock Sanitary Association, pp. 69-71, Chicago, Ill, USA, 1910.

[48] E. T. Faulder, H. M. O’Rear, C. E. Cotton, and C. C. Hisel, "Report of the special committee on tuberculosis," Journal of the American Veterinary Medical Association, vol. 83, pp. 518520, 1933.

[49] J. M. Hackney, "Tuberculosis and the dairy industry," in Proceedings of the 23rd Annual Meeting of the United States Livestock Sanitary Association, pp. 38-44, Chicago, Ill, USA, 1919.

[50] A. L. Olmstead and P. W. Rhode, "Not on my farm! Resistance to bovine tuberculosis eradication in the United States," Journal of Economic History, vol. 67, no. 3, pp. 768-809, 2007.
[51] P. Malcolm, "Problems of tuberculosis control and its relation to sanitary science and food hygiene," Journal of the American Medical Association, vol. 80, pp. 96-99, 1932.

[52] "Husbandry: at lenker's place," Time, 1931.

[53] S. E. Bruner, "Result of a project to determine the comparative value of the subcutaneous-intradermal tuberculin tests," in Proceedings of the 25th Annual Meeting of the United States Livestock Sanitary Association, pp. 107-113, Chicago, Ill, USA, 1921.

[54] U.S. Department of Agriculture and Animal and Plant Health Inspection Service, Bovine Tuberculosis Eradication Uniform Methods and Rules, US Government Printing Office, Washington, DC, USA, 2005.

[55] M. P. Ravenel, "The tuberculosis problem," in Proceedings of the 15th Annual Meeting of the United States Livestock Sanitary Association, pp. 62-76, Chicago, Ill, USA, 1911.

[56] A. Peters, "Obstacles to enforcing regulations requiring the tuberculin test in interstate cattle traffic," in Proceedings of the 37th Annual Meeting of the American Veterinary Medical Association, pp. 202-215, Saint Paul, Minn, USA, 1900.

[57] T. Smith, "A comparative study of bovine tubercle bacilli and of human bacilli from sputum," Journal of Experimental Medicine, vol. 3, pp. 451-511, 1898.

[58] A. D. Melvin, Hearings before the committee on Agriculture. Agricultural Appopriations Bill, Congress, Government Printing Office, Washington, DC, USA, 1909.

[59] A. D. Melvin, The 28th Annual Report of the Bureau of Animal Industry, Bureau of Animal Industry, Washington, DC, USA, 1913.

[60] J. A. Kiernan, "Report of the committee on tuberculosis of the United States Livestock sanitary associatio," in Proceedings of the 25th Annual Meeting of the United States Livestock Sanitary Association, pp. 92-106, Chicago, Ill, USA, 1921.

[61] J. A. Kiernan, "The accredited-herd plan in tuberculosis eradication," in Yearbook of Agriculture, vol. 1918, pp. 215-220, Government Printing Office, Washington, DC, USA, 1918.

[62] J. A. Kiernan, "Proposed regulations for accrediting herds of cattle," in Proceedings of the 21st Annual Meeting of the United States Livestock Sanitary Association, pp. 128-129, Chicago, Ill, USA, 1917.

[63] J. A. Kiernan, "Bovine tuberculosis being suppressed," in Yearbook of Agriculture, vol. 1926, pp. 180-183, Government Printing Office, Washington, DC, USA, 1926.

[64] J. A. Kiernan, "Tuberculosis eradication," in Proceedings of the 22nd Annual Meeting of the United States Livestock Sanitary Association, pp. 29-52, Chicago, Ill, USA, 1918.

[65] E. Hastings, "The eradication of bovine tuberculosis," American Journal of Veterinary Research, vol. 3, pp. 3-9, 1942.

[66] W. H. Feldman, "Animal tuberculosis and its relationship to the disease in man," Annals of the New York Academy of Sciences, vol. 48, pp. 469-505, 1947.

[67] D. L. Whipple and M. V. Palmer, "Reemergence of tuberculosis in animals in the United States," in Emerging Diseases of Animals, C. Brown and C. A. Bolin, Eds., pp. 281-299, ASM Press, Washington, DC, USA, 2000.

[68] M. J. Gilsdorf, E. D. Ebel, and T. W. Disney, "Benefit and cost assessment of the U.S. bovine tuberculosis eradication program," in Mycobacterium bovis Infection in Animals and Humans, C. O. Thoen, J. H. Steele, and M. J. Gilsdorf, Eds., pp. 89-99, Wiley-Blackwell Publishing Professional, Ames, Iowa, USA, 2nd edition, June, 2006. 

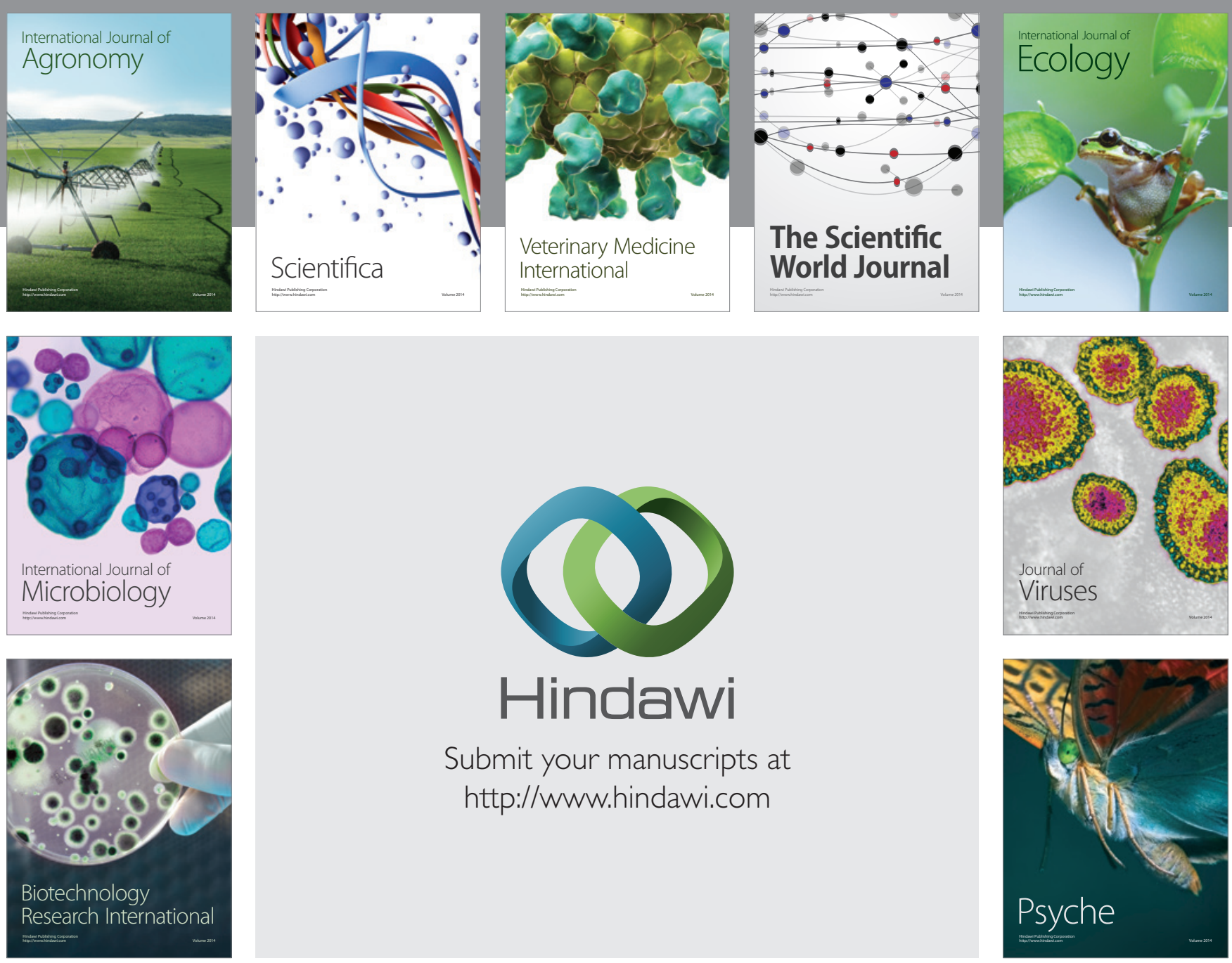

Submit your manuscripts at

http://www.hindawi.com
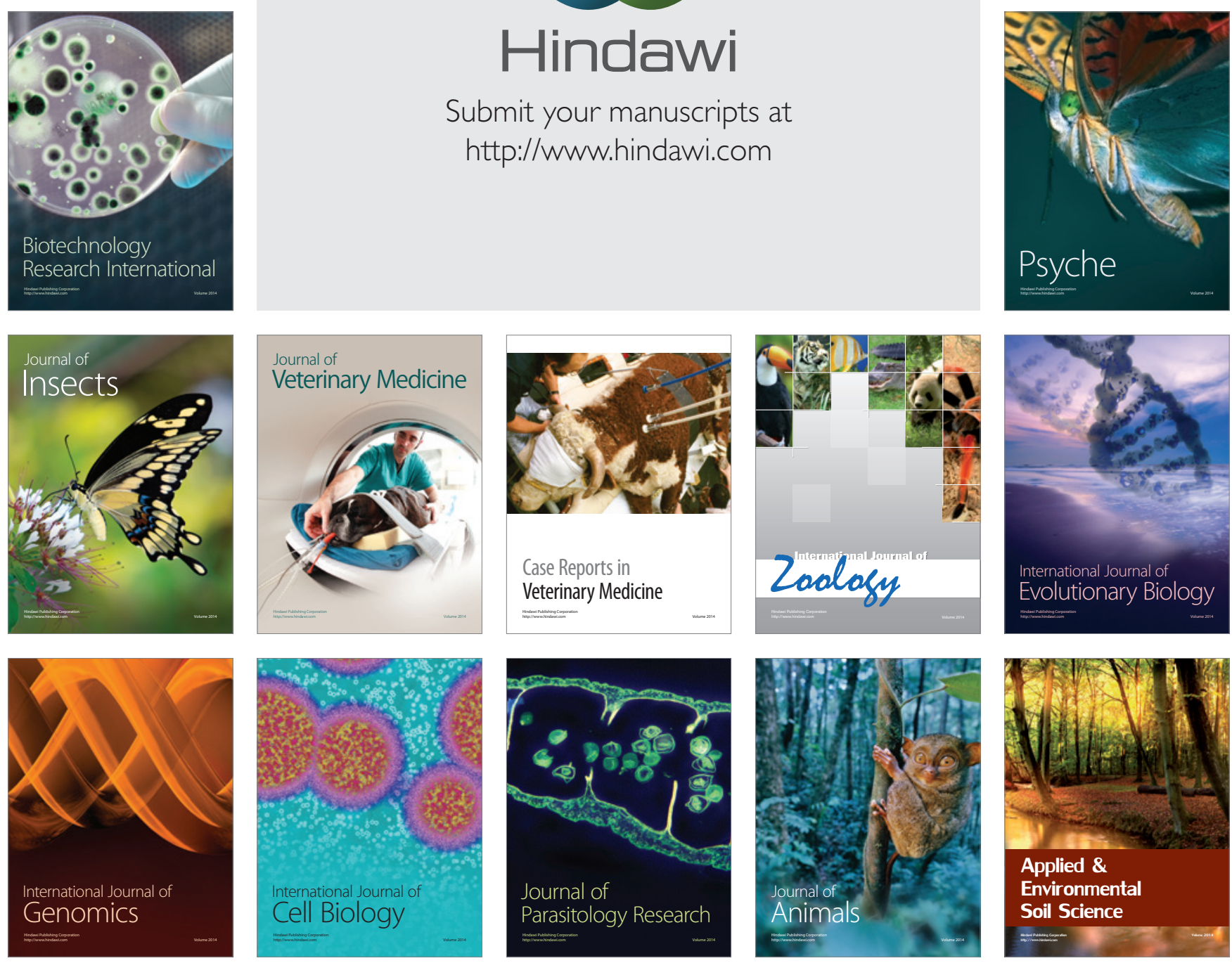